\title{
Heidegger's Discussion of "The Thing": A Theme for Deep Ecology
}

\author{
Lawrence W. Howe \\ The University of West Florida
}

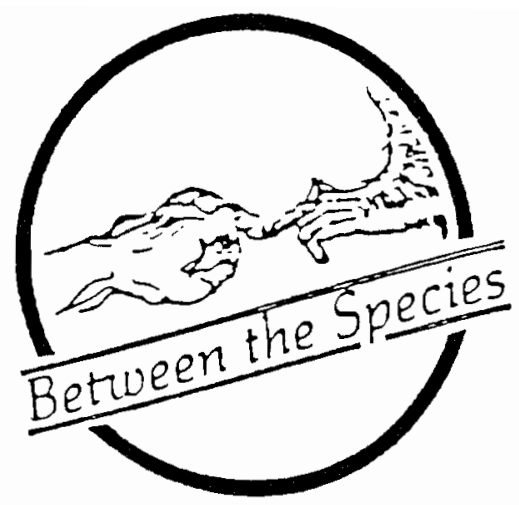

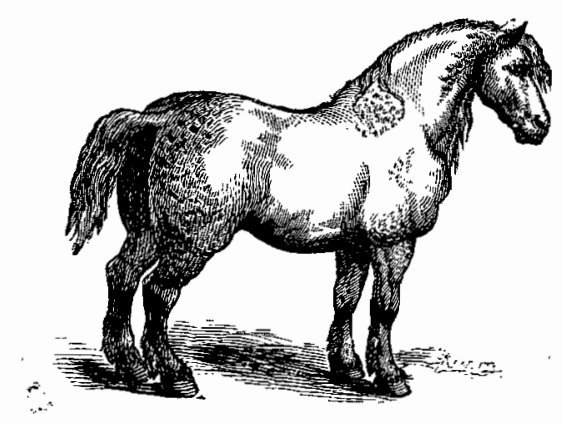

The history of environmental philosophy testifies to two strands of thought that stand in stark contrast to one another: anthropocentrism and biocentrism. In reaction to the traditional anthropocentric position, deep ecology has argued for a biocentric view of the humanity-nature relation. Against anthropocentrism, the deep ecologists have challenged the basic assumptions of the Western scientific-technological paradigm by proposing alternative paradigms that support biocentrism. One of the central issues confronting the development of an environmental ethic is the manner in which paradigms prefigure attitudes about nature. The approach of some deep ecologists is straightforwardly ontological as evidenced by the attempt to challenge scientific materialism as a paradigm about the nature of being.

In this paper I want to explore some of the ideas in the later writings of Heidegger in order to show how they may be placed in the context of deep ecology. His ontology, I believe, sponsors a biocentric view that regards all natural entities as possessing inherent value by virtue of their interrelation to the surrounding world. In particular, I will discuss Heidegger's position in his essay "The Thing." The distinction he draws between "thing" and "object" serves to lay bare the onedimensional mode of modern man that is largely the consequence of the quest to gain domination over nature through technology, and to thereby regard the natural world as a commodity.

Michael Zimmerman is one deep ecologist who has emphasized the importance of ontology for determining conduct towards nature. Carrying forward the ideas of Heidegger, he states the matter in the following way.

\begin{abstract}
Ontological issues pertain to the Being of entities, to that, what, and how they are. Every culture has a common way of understanding what things are, although this ontology is often so pervasive that people are unaware that they have a particular way of apprehending things. Usually, we think things really are the way they appear to us. But this naive idea doesn't stand up to critical scrutiny; the fact is that how things appear is determined to some extent by the ontological paradigm in the light of which they are seen. ${ }^{2}$
\end{abstract}

For Zimmerman, and for deep ecologists, ontology precedes ethics. We must first know what things are before deciding what norms of behavior we ought to adopt. The ontology that we are implicitly or explicitly committed to determines the way value is ascribed to

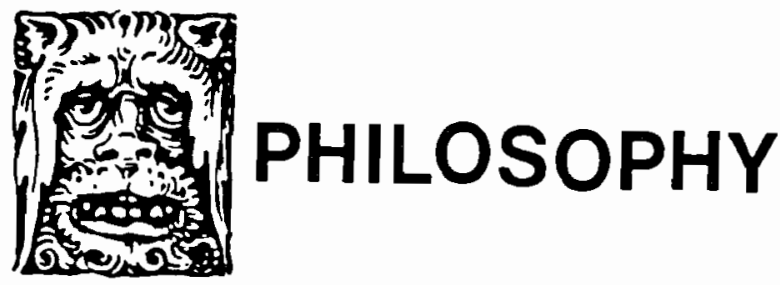


the natural world. Heidegger's ontology may contribute to deep ecology in two ways. First, by offering a critique of anthropocentric attitudes toward nature. Secondly, by cultivating a new perspective on the theme of interrelatedness between man and the natural environment.

Heidegger brings forward this ontology in his discussion of "the thing." Unlike a Platonic analysis into abstract entities that seeks to reveal eternal forms, Heidegger endeavors to uncover the nature of a thing that is more primordial than a sum of determinate and universal characteristics. He endeavors to reveal the particular concrete existent along with its interconnectedness to the world. His method is phenomenological in that it seeks to disclose that which shows itself in all its particularity. In contrast to modern technology which encourages a tendency to represent things as quantifiable objects to be controlled and dominated, Heidegger requests that we allow ourselves to be approached by the thing in its interrelation to the surrounding environment.

This perspective serves to underscore an essential theme from the deep ecology view in that it openly addresses fundamental assumptions about man's relation to nature. Things are not perceived as everyday objects when we allow the thing to present itself to us without pragmatic interests added to it. Rather than confronting the world, conditioning it, objectifying it for the sake of self interest, Heidegger recommends that we open ourselves to the world through attunement with it.

Heidegger warns against confusing everyday objects with a thing. When the confusion does occur, "things are no longer admitted as things"; and because of our calculative mode of thinking, they will not be able "to appear to thinking as things." 3 Everyday objects are conceptual constructs designed in conformity with our utilitarian interests. In contrast to this pragmatic posture, Heidegger suggests that we "let beings be," that means being attuned to the "unique ways in which entities present themselves or are. Letting something be can mean simply letting it alone, as in the case of not disturbing a wild place." 4 Indeed, there is more involved in authentic thinking about the environment than the thinking that regards it as a mere sum of objects possessing only instrumental value. Thus a Heideggerian approach to deep ecology is initiated through a radical re-thinking of the calculative-utilitarian mode of perceiving the world. Consequently, this inquiry brings forth a reappraisal of the way the world is intended. Heidegger writes,
When and in what way do things appear as things? They do not appear by means of human making. But neither do they appear without the vigilance of mortals. The first step toward such vigilance is the step back from the thinking that merely represents....

In this passage Heidegger critiques the traditional epistemological distinction between the human knower and the object known. According to that distinction, as Heidegger sees it, the thing is surreptitiously identified as nothing more than an object constituted by universal characteristics. That view has dominated Western thought since Plato. Because we look upon things as separate from us we fabricate a dichotomy between self and world. Once the dichotomy has been manufactured, the thing is regarded as a mere object; it has a "separate location" from any other entity in the environment. Thus, a thing such as a tree, for example, is represented as an object with the trait of "life" somehow added to it. By man's continual "forgetfulness" he tends to add characteristics to a thing and treat it as an object to be subdued by human control. This attitude is suggestive of the calculative thinking which artificially fabricates the thing with a view to quantifying it.

Through conceptually representing his field of experience, man objectifies the thing by reducing it to a set of concepts which artificially reconstruct the thing.? Formulas are devised so the thing can be regarded like any object that is translated into the formula's mode of expression. The aim of calculative thinking is to reduce the thing to elements that are common with elements of other objects. The thing is fragmented into parts, and though it is a unique entity, its uniqueness is blurred as a result of the fragmentation. This reduction has a utilitarian value because it enables us to grasp the thing in terms of universal concepts. As a consequence, things are represented as common objects. Because of the calculative mode, says Heidegger, "we separate subjects and objects, inside and outside, feelings and situations... These many divisions are not separate issues, since each involves the same type of conceptual construct of things...." In his essay, "Building, Dwelling, Thinking," Heidegger expresses the manner in which the essential nature of the thing has been lost.

Our thinking has, of course, long been accustomed to understate the nature of the thing. The consequence, in the course of 
Western thought, has been that the thing is represented as an unknown $X$ to which perceptible properties are attached. From this point of view, everything that already belongs to the gathering nature of this thing does, of course, appear as something that is afterward read into it. ${ }^{9}$

Throughout the history of Western thought we see a constant attempt to uncover the substance of a thing. Yet Heidegger suggests that a thing's underlying substance cannot be discemed from that which is gathered around a thing. The effort to delineate an independent substance disfigures the nature of a thing because its nature is part and parcel of its surrounding world.

Heidegger's investigation reveals the inauthentic attitude that man has developed toward the environment. "We ignore the intrinsic harmony of living beings, as well as whole biomes, for ontologically everything has been reduced to the level of raw material for production and consumption." 10

Although Heidegger has laid out the inauthentic attitude toward the environment, he offers an alternative for understanding the man/nature relationship. He illustrates this alternative by examining simple artifacts or natural entities as an example of a thing. Take a jug, says Heidegger, when we allow the being of the jug to come forth we observe that it presents itself as a process of "gathering in." It becomes the focus of a whole set of interconnections with its environment. However, the process of "gathering in" is only one feature of the jug's essence. Within the jug's capacity to contain is also the capacity to offer and pour drink. Granted that the jug has utility for men, but this artifact has a deeper significance.

The essence of the thing is that which gathers-up and comes-together, creating a presence of the fourfold unity of earth, sky, gods and men. The thing manifests the harmonious interplay of the fourfold in the world. The jug is a particular unity that exemplifies the integration of the earth, sky, men and gods. The thing assembles the unity of the fourfold, making possible their interrelation to one another. The thing, wrote one commentator, "evokes the 'quadrate,' gathers into unified presences the four moments, brings them into an abiding 'stand still,' to self-manifestation, to unconcealedness." "The earth, sky, men and gods are involved in one another so as to form a simple unitythe fourfold. Zimmerman explains these moments by saying that the earth is "the life-giving aspect of things that cannot and should not be violated," the sky is "the luminous aspect of the world necessary to draw forth what the Earth conceals," men are the ones who participate in the life process and the gods are an expression of the divine in a harmonious world..$^{12}$ The harmonious interplay of the fourfold constitutes the moments of the world through the presence of a thing.

Being a container, the jug gathers by taking and holding, but it further reveals the fourfold by pouring forth. Its out-pouring is a gift which regenerates the interplay of the fourfold. How is the fourfold gathered in the jug? The earth gathers since the drink comes from the earth's waters. The sky gathers because it offers the warmth of sun which is needed for the creation of the drink. The men gather since it is they who celebrate the joy of drinking. The gods gather since they are the ones whose honor is being drunk to. Thus, the jug reveals the mingling of the fourfold in the dimension of Being.

The interplay of the fourfold suggests a value to the world that contrasts sharply with the value attributed to it by the technological paradigm of anthropocentrism. For Heidegger the world is manifested as an opening which allows things to emerge; the world is that which comes forth and merges as a totality. Thus things are not lifeless atomic units detachable from their surroundings, rather they always bear an intimate relation to their environment. This view is compatible with the deep ecologists' emphasis on the interrelation of all things within a unifying matrix. For Heidegger, a thing is the center for the harmonious integration of the four moments of Being. Moreover, the world is revealed through each thing that comes to presence. Thus a thing is "more than a mere fact, more than something 'at hand' (vorhanden). It represents in a unique way the full richness of all 'regions' of Being as a whole."13 The thing so revealed is not an object of technological domination, nor is it dislocated from its environment. An understanding of the thing is intertwined with an understanding of the world.

Unlike the anthropocentric view that sharply distinguishes between man and nature, Heidegger sees man as an integral part of the fourfold. Humans are "portrayed as one of the four aspects needed to constitute an authentic dwelling place. Like a deer or jug or tree or bridge, a mortal can be a 'thing' that provides the nexus through which the other participating dimensions of the world can reveal themselves."14

The unity and interplay of the four members are further characterized by Heidegger as a "round dance" 
(gering) where each member of the fourfold assemble as participants of a unifying process. The round dance involves a double aspect. On the one hand, it presents a unity of the fourfold; the four gather appearing as a simple unity. As the fourfold gives the appearance of being a simple prevailing unity, it is characterized as a thing. On the other hand, the round dance also involves a dimension which consists of the fourfold in their interplay. This aspect of the round dance is called the world. Through the moments of the round dance the world and thing are gathered together, mutually configurated, not juxtaposed to one another. World and thing are two moments of one and the same process of the round dance.

It may be further pointed out that Heidegger's account avoids reductionism since both the thing and world retain their respective integrity. The world is not reduced to a mere collection of objects; the thing is not reduced to an atomic unit isolated from other entities. The fourfold, in the self-creating process of the round dance, are like threads which weave together the weft of the thing and world.

Heidegger has spoken of the fourfold as being a "whole infinite relation." None of the fourfold "stays and goes one-sidedly by itself. In this sense, none are finite. None are without others. In-finite, they hold themselves to each other, they are what they are from this in-finite relation, they are this whole itself." 15 The fourfold is an in-finite relation in that no one member has a unified and determinate nature in isolation from the other members. As in deep ecology, Heidegger emphasizes interrelations throughout nature. Things do not exist alone, they are what they are through their intrinsic relation to the environment.

Where does man stand in the presencing of the world? He emerges as one who lives with things - a participant member of the fourfold. The integrity of man is recognized by the fact that he is a necessary feature of, and belongs together with, the fourfold interplay. Heidegger's discussion certainly breaks away from the one-dimensional man nestled in the paradigm of mechanistic materialism. The technological orientation of contemporary man veils the presence of the thing by representing it as an everyday object cut off from the world and having nothing more than an instrumental value.

Heidegger's discussion of "thing" and "world" brings forth an ontological basis for interpreting the theme of interrelation that is an essential feature for deep ecology. His reflections serve to challenge anthropocentric attitudes toward nature that have emerged with the development of a mechanistic worldview. For deep ecology, he offers a way of regarding nature that is nonanthropocentric while boldly contemplating the possibility to "let beings be." For Heidegger, as for deep ecology, this means allowing a place for revealing man's interrelatedness and rootedness in Being as such.

\section{Notes}

'Heidegger, Martin. Poetry, Language, Thought. Translated by A. Hofstader. (Harper and Row, 1971), pp. 165-182.

${ }^{2}$ Zimmerman, Michael. "Implications of Heidegger's Thought For Deep Ecology," Modern Schoolman, Vol. LXIV, Nov. 1986, p. 21.

${ }^{3}$ Poetry, Language, Thought, p. 181.

${ }^{4}$ Zimmerman, "Implications," p. 32.

${ }^{5}$ Poetry, Language, Thought, p. 181.

${ }^{6}$ Martin Heidegger, What Is A Thing? Translated by W.B. Barton, Jr. and Vera Deutsch with an analysis by E.T. Gendlin. (Chicago, 1967), p. 263.

7 There is a striking similarity between Heidegger's distinction of an object (represented through calculative thinking) and a "thing"' (grasped by meditative thinking) and Bergson's epistemological distinction of analysis and intuition. For Bergson, analysis has a pragmatic interest in reducing an object to parts already known. On the other hand, intuition corresponds to Heidegger's meditative thinking where we grasp the thing--not as an object characterized by universal forms-but as a unique entity that bears an integral relation to its surrounding world.

${ }^{8}$ What Is A Thing?, p. 263.

${ }^{9}$ Poetry, Language, Thought, p. 146.

${ }^{10}$ Zimmerman, "Implications," p. 33.

${ }^{11}$ J.M. Demske, Being, Man, and Death. (University Press of Kentucky, 1970), p. 149.

${ }^{12}$ Zimmerman, "Implications," p. 33.

${ }^{13}$ Being, Man, and Death, p. 150.

${ }^{14}$ Zimmerman, "Implications," p. 33.

${ }^{15}$ Martin Heidegger, Elucidation of Holderlin's Poetry, translated by Keith Hoeller. (University of Alabama Press, 1976), p. 170. 


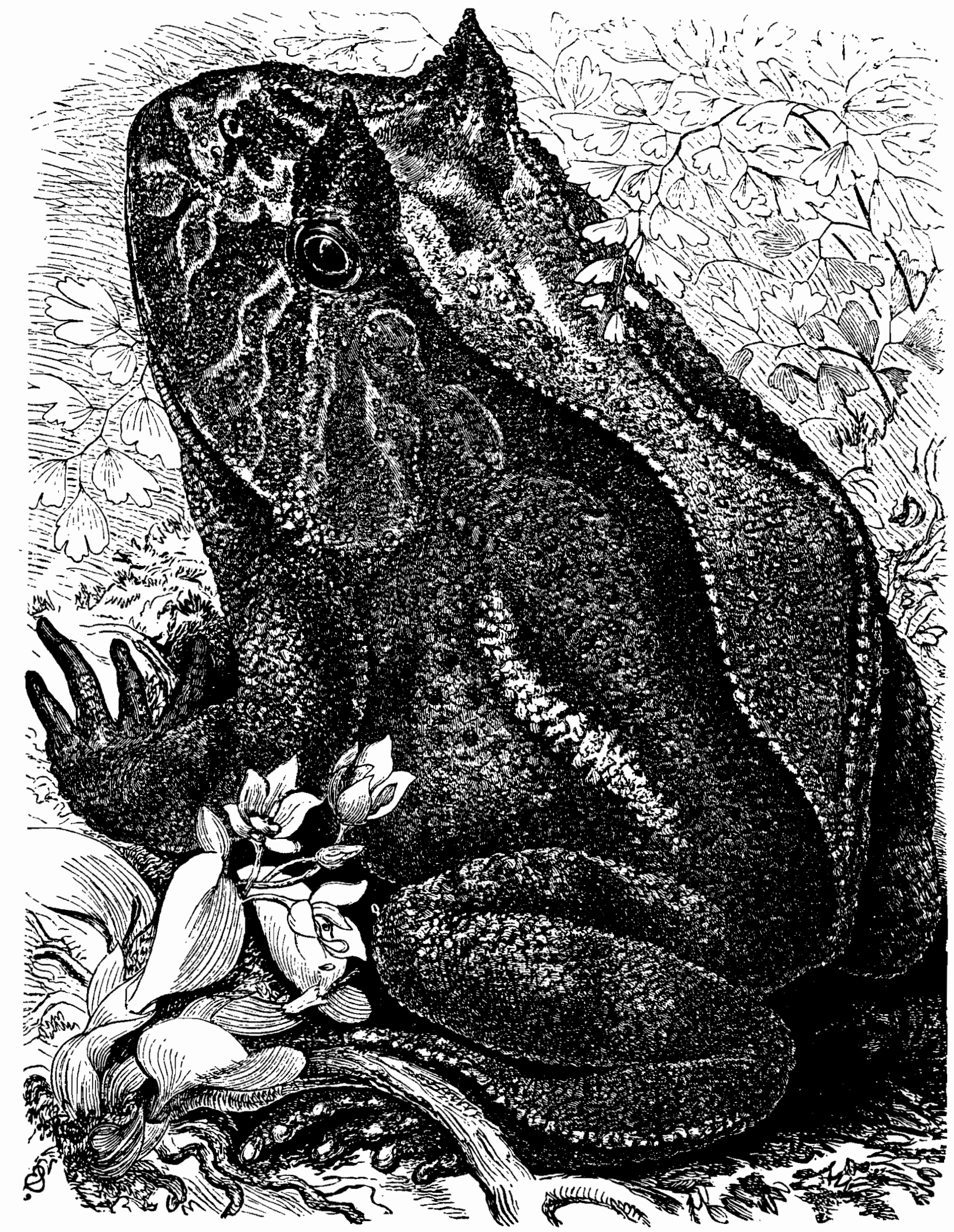

